\title{
Training of Teachers: Difficulties and Proposals in Mexico
}

\author{
Yulia Solovieva, Ana María Baltazar Ramos \\ Eduardo Alejandro Escotto Córdova and Luis Quintanar
}

Received: Sep. 4, $2017 \quad$ Accepted: Oct. 26, $2017 \quad$ Published: November 1, 2017
doi:10.5296/jse.v7i4.11805 URL: https://doi.org/10.5296/jse.v7i4.11805

\begin{abstract}
According to Vigotskian conception, teaching might be considered as a collective and joint dialectical process. Preschool and school psychological development of children occurs not in spontaneous way, but is directed by adults' attitudes and actions. Among such actions, concrete actions of children at school occupy the central place. Actions of teachers are based on their conception of psychological development and children's possibilities. Children never learn alone, but according to orientation and participation of adults. The presence or absence of the knowledge zone of proximate or actual development is crucial for the actions of teachers. From this perspective, it is important to learn about the methods of pedagogical preparation and training of teachers. The situation with such preparation in many countries in general and in Mexico particularly might be described as critical. Cultural and historical conception of human development and the concept of the zone of proximate development, proposed by L.S. Vigotsky is rarely taught and used in practice in traditional pedagogical institutions. Traditional methods of teaching, at all levels, are full of memorization, repetition and reproductive operations. Real and concrete cultural actions are absent both in Pedagogical Institutions and in Schools. The article describes original practice of attempts of organization of non-traditional type of preparation of teachers and to show how they can teach children. Experience in a small private school in the city of Puebla (Mexico) is included. The authors discuss qualitative achievements in teaching and learning based on activity theory and historic-cultural conception of development.
\end{abstract}

Keywords: teaching process, proposals for teaching, zone of proximate development, historical and cultural conception, teaching and learning process. 


\section{Introduction}

According to Vigotskian conception of psychological development of human being in infancy, teaching might be considered as a collective and joint dialectical process with participation of teachers and pupils. Success of learning depends on variety of complex social, economic, politic and administrative factors. Usually, one of the most important factors is not considered in the contents of Educational Reforms of many countries and this factor is the method of teaching and preparation of future teachers. This situation is serious and, according to our opinion, has to be considered form the point of view of historical and cultural conception of human development.

In his conception of historical and cultural development, Vigotsky supposes that the process of development is social and interactive in its profound nature. This position is true on all levels of development and education. Such levels might be pre-school age, school learning and latter professional training. On each level, the progress of pupils depends not only on their unique individual personality features, but also on the content, methods and style of organization of the whole process of education.

According to theoretical positions of historical and cultural psychology, founded by L.S. Vigotsky, pre-school and school psychological development of children doesn't occur in spontaneous way according to the laws of maturation, but is oriented and directed by adults' attitudes and intellectual actions. These attitudes and actions of adults (teachers, parents and older friends)are not always and not necessarily of chaotic, occasional or exceptional features.In reality, teachers use methods for care and teaching process of children according to different conceptions of development.

Vigotskian conception of development is one of such possible conceptions. This is unique conception, which considers children as equal participants of their learning activity by the usage of the concept of the zone of proximate development (Vigotsky, 1996). This conception was developed and continued in the works of other prominent psychologists, who introduced the concept of orientation into psychological theory and practice (Talizina, 1988; Galperin, 1998; Davidov, 2008). Other conceptions of development are related to other general psychological conceptions such as behaviorism, psychoanalysis and cognitive psychology. These are real options of paradigms, which might be used for introduction of the concepts of development.

The authors of this chapter, as followers of historical and cultural conception of development and activity theory are convinced that precisely this paradigm of development is very useful and might modify radically the way of solution of many practical problems of present and future education. What is happening now is the rising of total separation between the methods of psychological research and real application of the data of research in practice of education.

It is possible to say that psychologists all over the world, as representatives and followers of Vigotsky's conception don't have radical impact on practical aims of education. Mostly everywhere, the predominant approach for education at all levels is based on behaviorism. Children and young people have to memorize knowledge, repeat what the teacher says and 
present exams to be quantitatively qualified. Usually, the pupils forge the majority of data after presentation of exams. What really happens is that pupils are taught to memorize information instead of learning to use and to analyze essential information.

Such situation contradicts to position of activity theory and cultural development. The authors of activity theory and the concept of systemic process of learning with orientation insisted that the organization of learning process should be modified (Davidov, 2000; Galperin, 1998; Talizina, 1988, 2009). Important psychological and pedagogical experiments were conducted with positive results of application of new methods of conceptual thinking at school (Galperin, 2000). Not only social interaction is necessary mechanism of psychological development, but also the content and types of interaction used by adults and teachers for orientation (Solovieva, 2014).

According to L.S. Vigotsky and his psychological conception, the process of teaching and learning is the process, which conducts to psychological development in general. In Vigotsky's words, learning process is the basis of development. On the contrary, the famous opinion of Piaget is that learning process should be based on previous development and maturation. Such difference in opinion of both psychologists is often not noticed by modern representatives of the theory of social learning. Learning process is frequently understood as natural and spontaneous process, where only general social interaction in important.

Nevertheless, when readers directly study directly texts of Vigotsky, they might notice, that according to his position, psychological development doesn't occur automatically or spontaneously only by genetic or biological reason of maturation of central nervous system, but according to participation of human child in meaningful cultural activities. Such activities normally are already designed by society before the child starts to take part in them. The design and planning of such activities depend basically on the type of preparation and capacitation of adults who take part in this important process. It is possible to suppose that activities used in educational at pre-school and school institutions might be useful for psychological development, but also might be neutral and even might conduct to negative consequences in psychological development, personality and sphere of motivation of children.

Following this idea, the process of preparation of specialists who work with children in the sphere of education is an essential point of Vigotsky's approach for child's ontogenetic development. At the same time, this is a big problem of system of education of each country.

As for Latin America in general and Mexico in particular, we may say that specialists who work and provide research on the basis of historical and cultural conception are really invited for consulting the programs for teaching of psychology and education at university.

\section{Stimulation of early development at Zaragoza Faculty}

The system of pre-school education in Mexico might be considered as a field, in which some influence of historical and cultural approach of L.S. Vigotsky at practical level. The Secretary of Public Education doesn't assume any specific conception or theory of development. In programs and plans of studies for preparation of teacher for public pre-school institutions 
some reference of Vigotskian concepts might be found. The references are related to aspects of play, development and the role of speech in child's development.

During the period of school year 2015-2016 (SEP, National System of Statistics), the population of pre-school children was of 4, 124, 252 children; 3,436,538 among them were pupils of public pre-school institutions and 687, 714 were pupils of private pre-school institutions. 230,781 teachers in the total of 89,409 pre-school institutions attended these children.

In recent years, on the basis of administrative educational reform in Mexico, a large number of psychologists began to participate actively in the work of preschool institutions. This phenomenon is mostly observed in Mexico City and is not so evident in the rest of the country. The majority of psychologists who started to work in pre-school institutions have graduated from National Autonomous University of Mexico: the biggest and most prestigious public institution for superior education.

National Autonomous University of Mexico has 204,940 pre-graduated students and 28,638 postgraduate students (Statistic Agency of UNAM, 2016). The Programs for study of Psychology are distributed in three zones (campus): campus: Faculty of Psychology, Faculty of Superior Studies Zaragoza and Faculty of Superior Studies Iztacala. There are 12,317 students in these three campus including pre-graduated and post-graduated students. In all three campus there teachers who train students introducing some concepts from Vigotsky's approach. Specifically, Faculty of Superior Studies Zaragoza has thirty years of tradition of using of this approach with students.

In October 2016, Faculty of Superior Studies Zaragoza possessed 2,234 of students of psychology (Mendoza, 2016). These students had an opportunity to take classes in the area of educational psychology. This are offers different kinds of supervised practice. One of these supervised practices is the program of practice with pre-school children dedicated to early stimulation of development oriented by the model of the theory of historical and cultural development of L.S. Vigotsky.

This program assumes the conception of development, according to which child's development should be characterized by what the child is able to do with the external help of adults and other children. Psychological development isn't understood as the series of biological stages of maturation isolated from social interaction, but the tasks and abilities, which the child might achieve together with adults and other children at different neurobiological stages.

L.S. Vigotsky wrote about the concept of the zone of proximate development: "Psychologist, while assessing the process of development, should obligatory have in mind not only mature functions, but also the function in transition of development. Not only actual level, but also the zone of proximate development ...This divergence between mental age o level of actual development, which might be determined by the tasks fulfilled independently by child and the level, which the child might achieve, not by itself, but in collaboration, is what we call the zone of proximate development" (Vigotsky, 1993, p 238-39). 
The mentioned above idea, essential within Vigotskian approach, has powerful meaning for practice of proposals of programs for work with pre-school children. Pedagogical practice proposed and directed by Ana María Baltazar Ramos and Eduardo Alejandro Escotto Córdova at the Faculty of Superior Studies Zaragoza of National Autonomous University of Mexico (Mexico City). This program has an objective of practical preparation of students who are interested in the field of psychology applied to pre-school education. Especially, an emphasis is made on the aspects of prevention, stimulation and remediation as the fields of research in pedagogy and developmental psychology. The program was created in accordance with the plan of studies of Faculty of Superior Studies Zaragoza of National Autonomous University of Mexico.

The program of early stimulation, starting with children of the age of 6 months old has been prepared for such a purpose. The content of the program is related with different game activities. The main purpose of these games is to guide and regulate activity of children by inclusion of their parents into interactive tasks. The parents take part in all sessions and activities. The program is applied and supervised under direction of Ana María Baltazar Ramos and Eduardo Alejandro Escotto Córdova.

All activates are planned for 2 sessions per week during 5 hours per day. The students organize different professional actions supervised by the teachers. Examples of these actions are assessment and intervention in development from the perspective of psychology and education. The objective of such actions consists in the totality of recognition of meaningful educational situations and satisfaction, in possible manner, of diversity social and educational needs of population. These needs include consideration of unique nature of each subject, social group and community in relation to learning process on the basis of respect of globalism and complexity of nature of each process.

The scenery of the work is multidisciplinary clinic "Zaragoza". This place offers the Program for Stimulation of Early Development, entirely oriented on the basis of Vigotsky's approach for human development. The students who take part in the program are encouraged to study and produce new knowledge for fulfillment of developmental assessment and diagnosis, elaboration of strategies for intervention, capacitation and complementary work for parents and teachers of regular schools and create methods for work directly with pre-school children.

The students of educational Psychology of 7th and 8th semesters(two last years of university studies) take part in research together with practice work with children within the Program for Stimulation of Early Development the age of children included in the program is from 0 to 6 years. The children included in the program do not present any difficulties either in biological or social aspects of their development. All parents of children assist to the Clinic "Zaragoza" voluntary.

The work on the Program dues to following principles of historical and cultural approach in psychology offering structural activities, guided by adults according to the necessities of children. The dominant activity is playing activity as rector line of development at pre-school age. The usage of playing activity permits to use the function of external regulation by speech 
and actions with objects of adults in order to include children in realization of shared playing tasks.

The tasks proposed in the program of stimulation have the following characteristics:

5 The tasks are of multisensory nature including possibilities of inclusion of visual, hearing, tactile, smelling and taste modalities and movements as well.

5. The tasks for assessment are carried out each month in order to take into account stage of development of children. The tasks of assessment are constructed according to the concept of determination of the zone of actual development in order to find necessary mechanisms for helping in all cases.

All sessions and tasks has to be carried out on the following basis:

(5) The tasks has to be pleasant and interesting for children and help to enrich emotional experience of children and guarantee acquisition of new tools for proximate development.

(5) The tasks have to be structured and planned and include two areas of development as minimum. The areas of development are marked by plans of development and include areas of: motor sphere, cognition, language, socialization and auto-help.

(5) The tasks have to be simple and pleasant for adults and kids, searching for global development. The tasks have to avoid situations of frustration, tension, anxiety and anger. The tasks are directed to stimulation positive aspects of child's personality, to increase self-confidence and self-knowledge and own abilities, capacities and limits. The work of children, in all aspects, has to be positive experience.

5 The tasks are always designed on the basis of interactive games of social roles and free playing. Such games are provided on the basis of impulse of tendency for curiosity, independent exploration and imagination.

5 The tasks have to be of short duration and include variety of options. The tasks have to be adapted to characteristics of child; the child normally has to move actively in space and to change its action every moment.

\section{Implementation of the program}

\section{Phase 1}

Duration of the first stage is of four weeks. The sessions took place two times per week during 5 hours per day. All students are previously prepared according to the principles of the Program for Stimulation of early development. Such capacitation of the students takes place during one Semester of University studies. The students study fundamental concepts of historical and cultural approach such as: development characterized by the zone of actual development and zone of proximate development (Vigotsky, 1979). The zone of proximate development implies two moments: actions of the child, which the child might fulfill with the help of an adult and the actions of an adult directed to orientation of the child (Vigotsky, 
1996). On the contrary, the zone of actual development represents only actual development or actions, which the child might carry out without any adult's help.

The zone of actual development might be studied by the usage of strict psychometric batteries. The main purpose of these batteries is to verify, what the child can do without any external help. On that reason, the students learn to use some batteries; such are Guidance Portage for pre-school education (Bluma, Shearer, Frohman, \& Hilliard, 1978), The Wechsler Intelligence Scale for pre-school children and primary school-III(Wechsler, 2002) and the Scale of development Merry Palmer, (Roid \& Sampers, 2004). The main purpose of these scales is to discover the zone of proximate development of children.

Afterwards, the importance of playing activity, imagination, creativity, drawing and symbolic development is revised by the students as central lines of child's development from historical and cultural perspective. These topics are introduced with the objective to understand the importance of the zone of proximate development and to design proper activities for stimulation of development of children.

\section{Phase 2}

After the period of capacitation, the Project of the program is presented to the students. The students make their own decision about voluntary participation in the program. The teacher makes also their decision about capacities of the students who wish to take part in the program. The selection of children for the program has place also during this phase.

\section{Phase 3}

After selection of students and children, each university student receives two children for work. The student has to fulfill initial assessment and determine the basis of development and to start with planning of the activities. All activities has to correspond to the principles describes above. The activities are of three modalities: 1) activities in groups; 2) individual activities and 3) activities for home.

1) Activities in-group are designated for the areas of socialization and motor sphere. The duration of activities in-group is of 50 minutes. All participants of the program should be included with all the parents present in the sessions. Normally two kinds of objectives should be accomplished in such activities in groups. Examples of such activities might be: respect of turns and climb the stairs. Different tasks might be used in activities in-group. For example, such activities might be: pass the tunnel made of paper of boxes, chairs and tables; take the ball; jump five times; pass the ball to the person on the right side of the tunnel; use the steps of the stairs, form behind own father and make the bridge using own bodies for other friends.

2) Individual activities are directed more to the areas of cognition and language. At the beginning of each session, each student would explain to the parents about the goals of the tasks. In all sessions, both parents and student would work together with the child in a joint manner. These activities might include diverse tasks or parts with one or two separate goals. For instance, such goals might be cut different paper figures, identify triangle or square, 
circle and so on. A game with toys might be organized with the purpose "to take the passengers to bath in the swimming pool".

The first part of the session might be dedicated to the task for cutting paper in order to obtain conic figures or round figures. Adults show the child how to cut such figures. Afterwards, the figures might be put on the board to form some complex figures such as cars or buildings. Next, the parents might be asked to paint the wheels of cars with yellow color and windows with red color. Later one, some toys might be used to represent passengers who will used the bus and the cars. Blue color might be used to paint swimming pool and the passengers would arrive and take a bath. Normally, five different steps or objectives are designed for each activity with parents and child and explained by the student.

During this activity, verbal regulation of the whole action is present at all moments. The students show and the parents learn how to guarantee verbal regulation of all activities with the child.

Specific periods of time are normally planned for all tasks. After 45 minutes, the child would be asked to help to clean the whole space and put all objects in correspondent boxes and the session ends. All participants determine if the objectives were achieved or not properly. On this purpose, student and parents would ask the child about the content of the fulfilled game. The following examples of questions might be used: What did we do? How did we play? Which were the shapes of the wheels and the heads of the passengers? Which was the color we used for the triangles and for the squares?

It might be possible that some objectives might be achieved and some might fail in some sessions. For example, child might forget the circles or triangles and so on. Some other objectives might be defined, which were not considered in the plan of the tasks. According to this final reflection, next future activities for proximate sessions would be designed.

As for home activities, each student would dive some specific tasks for work at home. Once per weak, each student gives the parents the list of games in order to stimulate self-help and independence. For example, the student might considered to explain how to eat with the spoon, who to make a sandwich, do owns necessities. The parents could be encouraged to play games with social roles as "doctor", "cook" and so on. Such kinds of activities would be explained to the parents with all details and printed instructions would be given to them. The parents are asked to write down what they have done during the weak, what did the child did or said during the games. The parents have to return written experience to the student next session.

In case if some parents or children show inappropriate attitudes during the sessions, special explanations would be provided. For example, the child might hit the other, cry or shout loudly in an ugly manner or drop things. The parents would be explained how such behaviors might be treated. Another example might be that the parents might show absence of respect or patience and star to behave themselves in a desperate manner, the students would pay their attention and explain positive solutions. 


\section{Phase 4}

Each month correspondent student in order to determine achievements and failures and to choose more positives choices for activities assesses each child. In necessary cases, the activities might be modified or not for future month.

All activities and performance of the students, parents and children are video recorded. The tapes are conserved in "boxes of evaluation". Specific observations and recommendation for the sessions during the fulfillment of the program are constantly provided. The boxes contain also plans for realization of activities in-group, individual activities and home tasks of all children. All boxes contained card with identification, letter of agreement signed by parents and protocols of assessments.

\section{The role of assessor of the program}

The role of assessors and coordinators of the program starts with preparation and capacitation off the students. After this faze, assessor supervises the whole work of the student, helps to plan the sessions and types of activities. In necessary cases, the assessor might take part in some activities together with students. The assessor revises activities in-group, conclusions of assessment, recommendations for parents. Finally, assessor has to give marks for students' work.

During the sessions with parents, the assessor supervises explanations of the student. Afterwards, the assessor discusses with the students all aspects of the work and makes necessary comments and corrections. Specific session for retro alimentation and discussion of cases are carried out at the university.

Two weeks before the end of the work with the program complete analysis of the practice is organized. Each student present his/her experience of work with correspondent cases and makes some conclusions and reflection.

The program of Stimulation of Early Development is quite popular among in Mexico City. Not all children can be included by different reasons (space, quantity of students and assessors). The parents have to make lists in order to wait for the place within the program or next year and parents usually recommend to the others to take part in the program. At the moment of preparing of this chapter the program exists for five consecutive years at the University. The program receives economic support as the Program of Research of National Autonomous University of Mexico.

Important ideas proposed by L.S. Vigotsky in the field of human development has to be shown and applied in the filed of education. The stage of the early infancy is the period of time when it is very important to guarantee some empiric proves of this model of development. Specialists in psychology have to start to be properly trained from the point of view of the theory and the practice of the conception of the zone of proximate development and verbal regulation of activity. Such regulation starts from external joint plan of activity and later on, passes on the plan of internal activity. Playing activity is a great opportunity for child to be involved in shared cultural activities. The Program of Stimulation of Early 
Development Zaragoza of the Faculty of Superior Studies of National Autonomous University of Mexico has opened such opportunity.

\section{Vigotskian conception in modification of education}

\section{The case of Kepler College in Puebla}

The authors of the article have made a decision of trying to create new strategies and methods for teaching in Mexico. This process includes not only development of methods, but also changing of minds of teachers and "teaching of teachers". In the words of Leontiev, this is changing of the "image of the world" of the teachers (Leontiev, 1984).

Our own experience in Mexico is positive on this path and interesting results have been obtained. The method for initial introduction of learning and reading was created and applied at the first grade of primary school for Spanish language (Solovieva \& Quintanar, 2011). The method of introduction of English writing process starting from the second grade of primary school was introduced (Solovieva, 2015). The continuation of systemic approach for development of writing of conceptual grammar concepts was created by one of the authors of this chapter (Solovieva, 2016).

In relation to pre-school age, the method and strategies of formation of activity of games with social roles was provided at the first three grads of pre-school education was gradually introduced (Solovieva \& Quintanar, 2012). The formation of graphic activity and drawing was used as a strategy for working with concrete images of objects, spatial orientation and verbal development with children of the age from 3 to 6 years in pre-school level. All these methods were used in our research and pedagogical psychological practice in small private pre-school and school institution (Solovieva \& Quintanar, 2016). All these strategies were created and applied according to systemic psychological approach within activity theory and concept of historical and cultural development.

The results were obtained within research and presentation of Master Degree dissertations in the Master Program of Neuropsychological Diagnosis and Rehabilitation created of the Faculty of Psychology of Autonomous University of Puebla by Luis Quintanar in 1994. Since that time, the whole program with theory of neuropsychological developmental has been followed from the point of view of historical and cultural approach of L.S. Vigotsky, A.R Luria and their school. 20 generation and the total of 180 students have been graduated in the program. There are representatives from different countries of Latin America among them.

The problem with these results was always that they were local, sporadic and dependent on conceptual profound preparation of specialists who learn these new methods. It was necessary to think about more systematic and organized implementation of created strategies in groups of children. This situation has changed with creation of Kepler College in the city of Puebla. The authors of the article (Yulia Solovieva and Luis Quintanar) have introduced complete methodology for pre-school age, including children form 3 to 6 years old. The methodology is totally based on historical cultural psychology of child's development and activity theory. The sessions are planned during a weak and include different kinds of activities, which conduct to development of new psychological formation of pre-school age. 
They are daily activity for groups of children of first, second and third of pre-school grades. All activities involve all children in groups and are guided by an adult. Duration of activities is 50 minutes approximately.

These basic activities are: plays with social roles; gradual introduction of drawing by stages; analysis and representation of tails and stories.

1) Plays with social roles. Plays with social roles include symbolic components, which are different according to complexity in three grades. The teacher takes part in plays as one of participants and, at the same time, provides all necessary orientation, models and explanation for the children (Solovieva \&Quintanar, 2012).

2) Gradual formation of drawing. Introduction of drawing starts with material level by comparison of essential features of objects and toys. Later one, children learn symbolic representation of actions by gestures in order to pass to drawing of lines and elemental shapes. On the next stage children starts to generalize shapes of concrete objects and learn how to draw them. On the most complex stage children create different landscapes and variants of still lifeand make illustration for fairy tales and short stories(Solovieva \&Quintanar, 2016).

3) Analysis representation of tails. In these sessions, an adult reads fairy tails loudly with artistic expression to children. During the reading and afterwards, different questions are proposed with the objective of identification of characters, features, actions, situations and reasons of actions and so on. The complicity of the texts differs from year to year. Children make decisions and proposals for selections of stories and for comparison of features and characters. Different types of representation of characters and actions take place. The total of one hundred stories and tails or even more normally are discussed and dramatized by children during school year.

Other activities include games with objects for introduction of English language (Solovieva, 2015), lessons of physic education and arts. These activities change from day to day.

Our experience with implementation of these kinds of sessions shows that children acquire new formations of psychological age as voluntary activity, imagination, emotional involvement in activities, curiosity, high level of verbal expression in dialogues and broad possibility for usage and creation of symbolic means. Our program is totally new in Mexico and we are the unique institution of pre-school education based completely on historical and cultural psychology and activity theory. Our main difficulty is that the program doesn't consider the planning and lines of official program for preschool education and school inspectors are not happy with our proposals.

On the other hand, the positive part is that the teachers who start to become part of our program express that they can't imagine their lives without this understanding of development any more.

\section{New proposals for organization of learning process of teachers}




\section{Al Macrothink}

Not all kinds of interaction or all kinds of learning process conduct to development or to acquisition of new concepts and ways of teaching. According to Talizina (2009), only those kinds of learning lead to development, which is based on the concept of the zone of proximate development proposed by Vigotsky (1996).

In our opinion, it is necessary to provide different kind of preparation of teachers in order to guarantee modification of methods of children's development. To accomplish such an objective, two different modalities of interactions have been proposed.

One of the proposals consists of preparation and organization of broad circles of lectures (structures courses) with specific topics as a kind of specialization for teachers. These courses of specialization imply preparation and selection of topic and content of lectures. The duration of the circles is of 120 hours in periods of ten months. The lectures are divided in 10 blocks of ten hours exposed by one lecturer as expert in theoretical, methodological and practical aspects of the topic. Ten different options of courses of lectures were created during last ten years and are exposed by petition in different cities and institutions in Mexico.

As an example, we present the following structure of the course entitled "Psychological development at pre-school age". The ten blocks of the course are:

1. Theoretical basis of historical and cultural approach in psychology.

2. Pre-school age as one of the periods of psychological development.

3. Development of personality during pre-school age.

4. Intellectual development at pre-school age.

5. Verbal development and strategies for assessment in pre-school age.

6. Development and assessment of voluntary activity.

7. Development of playing activity.

8. Acquisition of symbolic function at pre-school age.

9. Formation and assessment of elements of mathematic abilities.

10. Strategies of assessment of psychological development at the end of pre-school age.

The goals of the course are as follows:

1. To introduce and to analyze advances of historical and cultural approach in relation to the topic of development in infancy.

2. To present elements of theory and methodology for analysis of process of development at pre-school age.

3. To share general strategies for assessment of development. 
4. To establish criterion for early detection of difficulties and ways for correction at pre-school age.

The process of studies during the course includes reading of specialized literature, discussions and reflection in groups, elaboration of proposals for assessment and implementation of creative tasks. All topics and concepts are introduced from the point of view of historical and cultural approach to human development and activity theory (Talizina, 2007). The authors of the article believe that there is no need of separation on these conceptions. Separate study of Vigotsky's work only with no inclusion of posterior development of this approach within activity theory makes no sense and has no practical outcome. The authors are conscious that everybody in academic community of historical and cultural psychologists does not share this point of view, where some of the authors claim for the total separation of Vigotsky and next generation of representatives of activity theory is total (Zinchenko, 2002; Gonzales-Rey, 2006). In our opinion, this separation is artificial and superficial.

Another option is gradual inclusion of teachers in activities with gradual methodological preparation in practice in our Kepler School (www.colegiokepler.edu.mx). This second option is might be the best option, but is restricted to only one College, in which it is possible to provide constant supervision and methodological changes.

Described activities are totally new in Mexico and other countries of Latin America and are against of predominant traditional way of thinking and understanding of the purposes of learning process. At the same time, a lot of teachers and psychologists are engaged in our proposal and have initiative of participation in this modification of learning process.

The authors of the chapter are sure that the process of changing of methodology of learning involves children and adults together, where teachers might also learn together with children. Modification of learning process is dialectical shared interaction, which has to be studied according to its structure, content, participants and social results.

\section{References}

Agenda UNAM. (2016). http://www.planeacion.unam.mx/Agenda/2016/disco/

Bluma, S., Shearer, M., Frohman, A., \& Hilliard, J. (1978). Guía Portage de educación preescolar.Manual. Wisconsin, Cooperative Educational Service Agency.

Davidov, V.V. (2008). Lectures on general psychology. Moscow, Academia.

Galperin, P.Ya. (1998). Psychological activity as an objective science. Moscow, Institute of Pedagogical and Social Sciences.

Galperin, P.Ya. (2000). Four lectures on psychology. Moscow, High school.

González-Rey, F. (2006). Investigación cualitativa y subjetividad. Guatemala, ODHAG.

Leontiev, A.N. (1984). Activity, consciousness, personality. México: Cartago. 


\section{Macrothink}

Journal of Studies in Education

ISSN 2162-6952

2017, Vol. 7, No. 4

Mendoza, N.V.M. (2016). Gestión 2014-2018: Segundo Informe. http://www.zaragoza.unam.mx/portal/wp-content/Portal2015/InformesGestion/archivos_gesti on/II_Informe_14-18.pdf

Roid,G. \&Sampers,J. (2004).Merril-Palmer-R, Escala de Desarrollo. España, TEA.

SEP (2017). National System of Educational Statistics. (consulted on April 13 2017). http://www.snie.sep.gob.mx/estadisticas_educativas.html

Solovieva, Yu. (2014). Intellectual activity from historic and cultural paradygm. Mexico: CEIDE.

Solovieva Yu. (2015). Estrategias introductorias del lenguaje escrito en el idioma inglés. México: Plaza y Valdés.

Solovieva Yu. (2016).Enseñanza del lenguaje escrito. México: Trillas.

Solovieva, Yu., \& Quintanar, L. (2011). Enseñanza de la lectura. Método práctico para la formación lectora. México: Trillas.

Solovieva, Yu. \& Quintanar, L. (2012). La actividad de juego en la edad preescolar. México: Trillas.

Solovieva Yu., \& Quintanar L. (2016). El dibujo como actividad formativa en la edad preescolar. México, Trillas.

Talizina, N.F. (1988). Direction of the process of acquisition of knowledge. Moscow: Moscow State University.

Talizina, N.F. (2007). The essence of the approach of the activity in psychology. Metodología e Historia de la Psicología, 2(4), 157-162.

Talizina, N.F. (2009). Activity theory applied to learning process. Mexico, Puebla Autonomous University.

Vigotsky, L. (1979). The development of higher psychological processes. Barcelona. Crítica.

Vigotsky, L. S. (1993). Thought and Language. Selected Psychological works, Vol II. Madrid, Visor.:9-348.

Vigotsky, L. (1996). Selected Psychological works. VolIV. Madrid, Visor.

Wechsler, D. (2002).Wechsler Intelligence Scale for Preschool and Primary Levels-III. Mexico, Manual Moderno.

Zinchenko V.P. (2002). Bases psicológicas de la pedagogía. Moscow, Gradariki. 